\title{
Systematic Development of Eutectic High Entropy Alloys by Thermodynamic Modeling and Experimentation: An Example of the CoCrFeNi-Mo System
}

\author{
Muhammad Mukarram, M. Awais Munir, Mohammad Mujahid (D) and Khurram Yaqoob*(D)
}

check for updates

Citation: Mukarram, M.; Munir, M.A.; Mujahid, M.; Yaqoob, K. Systematic Development of Eutectic High Entropy Alloys by

Thermodynamic Modeling and Experimentation: An Example of the CoCrFeNi-Mo System. Metals 2021, 11, 1484. https://doi.org/10.3390/ met11091484

Academic Editor: Babak Shalchi Amirkhiz

Received: 15 June 2021

Accepted: 28 July 2021

Published: 18 September 2021

Publisher's Note: MDPI stays neutral with regard to jurisdictional claims in published maps and institutional affiliations.

Copyright: (c) 2021 by the authors. Licensee MDPI, Basel, Switzerland. This article is an open access article distributed under the terms and conditions of the Creative Commons Attribution (CC BY) license (https:// creativecommons.org/licenses/by/ $4.0 /)$.
School of Chemical and Materials Engineering (SCME), National University of Sciences and Technology (NUST), H-12, Islamabad 44000, Pakistan; mmukarram06@gmail.com (M.M.); awais.mn93@gmail.com (M.A.M.); drmmujahid@gmail.com (M.M.)

* Correspondence: khurram.yaqoob@scme.nust.edu.pk

\begin{abstract}
Face centered cubic (FCC) high-entropy alloys (HEA) exhibit excellent ductility while body centered cubic (BCC) HEAs are characterized by high strength. Development of fine twophase eutectic microstructure (consisting of a tough phase such as fcc and a hard phase such as bcc/intermetallic) can help in obtaining an extraordinary combination of strength and ductility in HEAs. Designing eutectic high entropy alloys is an extremely difficult task for which different empirical and non-empirical methods have been previously tried. In the present study, the possibility of developing a eutectic microstructure by the addition of Mo to $\mathrm{CoCrFeNi}$ was evaluated by calculation of the pseudo-binary phase diagram. Experimental results validated the presence of eutectic reaction in the calculated phase diagrams; however, small changes in the calculated phase diagrams were proposed. It has been shown that calculated pseudo-binary phase diagrams can provide a very good starting point for the development of eutectic HEAs and help in exponentially reducing the amount of experimental effort that may be required otherwise. Eutectic mixture consisting of FCC (A2) phase and intermetallic phases ( $\sigma$ and $\mu$ ) was successfully obtained by the addition of Mo to the CoCrFeNi system. The development of the eutectic microstructure showed a profound effect on the mechanical properties. Hardness of the samples increased from $150 \mathrm{HV}$ for $\mathrm{CoCrFeNiMo}_{0.1}$ to $425.5 \mathrm{HV}$ for $\mathrm{CoCrFeNiMo}_{1.0}$, whereas yield strength increased from around $218 \mathrm{MPa}$ for $\mathrm{CoCrFeNiMo}_{0.1}$ to around $1100 \mathrm{MPa}$ for $\mathrm{CoCrFeNiMo} \mathrm{C}_{1.0}$.
\end{abstract}

Keywords: thermodynamic modeling; eutectic high entropy alloys; scanning electron microscopy; XRD; strength; ductility; compression test

\section{Introduction}

Conventional alloys are currently used for the majority of structural applications. Some of the common examples include the use of aluminum alloys and titanium alloys for applications requiring high strength/weight ratios (aerospace industry) [1], steels as a loadbearing material for applications requiring high strength and ductility at low cost [2-7], cobalt-based alloys for biomedical applications [8-10], and nickel-based superalloys for applications requiring high resistance to mechanical degradation at elevated temperatures [11,12]. It is believed that the conventional alloy design approach has more or less reached its limits and cannot meet the requirements of demanding structural applications. The concept of high-entropy alloys was introduced in $2004[13,14]$. Unlike conventional alloys, they contain five to thirteen major alloying elements in equal proportions [15], and in most cases were found to possess single-phase microstructures (FCC [16,17], BCC [18,19], hexagonal closed packed (HCP) structure [20,21]). Increased stability of the solid solutions in high-entropy alloys was attributed to the high entropy of mixing that lowered their relative Gibbs free energy and stabilized them [14,22-24]. High-entropy alloys have shown a superior combination of physical and mechanical properties in comparison to 
their conventional alloy counterparts. Some of the outstanding mechanical properties of high-entropy alloys include high wear resistance $[25,26]$, high strength even at high temperatures $[18,27,28]$, tremendous thermal stability [27-29], and good corrosion resistance [30-33]. Courtesy of their outstanding combination of mechanical properties, HEAs are considered as promising candidates for a diverse range of advanced engineering applications, such as aero-engines [34,35], super conductors [36,37], and nuclear reactors [38,39].

Demanding structural applications require alloys with extraordinary combinations of strength and ductility. Most of the previous work on HEAs was dedicated to the development of either single-phase FCC HEAs and/or BCC HEAs [40-43]. Finding the aforementioned balance of strength and ductility through the development of single-phase HEAs seems difficult. A number of attempts, including the development of eutectic highentropy alloys (EHEAs), have been carried out to overcome the strength-ductility tradeoff. High-entropy alloys undergoing eutectic reaction $\left(\mathrm{L} \rightarrow \mathrm{Solid}_{1}+\mathrm{Solid}_{2}\right)$ are expected to benefit from the properties of HEA matrix as well as from the characteristics of eutectic microstructure [44-46]. The fine distribution of a tough and a hard phase obtained through eutectic reactions in HEAs can help in obtaining alloys with significantly high strength and ductility. The first eutectic high-entropy alloy $\left(\mathrm{AlCoCrFeNi}_{2.1}\right)$ consisting of a ductile FCC and hard BCC phase was designed and synthesized [47] in 2014 and exhibited an excellent combination of ductility and strength. In addition to good mechanical properties at ambient temperatures, it also showed a better combination of properties even at a temperature of $700^{\circ} \mathrm{C}$. Besides its excellent combination of mechanical properties, the developed EHEAs showed excellent castability [46,47], resulting in the successful production of superior grade industrial scale ingots with excellent chemical homogeneity. Considering the extraordinary combination of mechanical properties obtained in EHEAs, the possibility of developing eutectic microstructures has been evaluated in several other systems, including $\mathrm{AlNi}_{2} \mathrm{CrFe}$ [48], $\mathrm{AlCo}_{2} \mathrm{CrFeNi}_{2}$ and $\mathrm{AlNi}_{3} \mathrm{CoCrFe}$ [49], $\mathrm{Al}_{19} \mathrm{Co}_{15} \mathrm{Cr}_{15} \mathrm{Ni}_{51}$ [50], $\mathrm{Fe}_{35} \mathrm{Ni}_{25} \mathrm{Cr}_{25} \mathrm{Mo}_{15}$ [51], $\mathrm{Fe}_{20} \mathrm{Co}_{20} \mathrm{Ni}_{41} \mathrm{Al}_{19}$ [52], $\mathrm{CoCrFeNiTa}{ }_{0.395}$ [53], $\mathrm{Co}_{2} \mathrm{Mo}_{0.8} \mathrm{Ni}_{2} \mathrm{VW}_{0.8}$ [54], $\mathrm{Nb}_{25} \mathrm{Sc}_{25} \mathrm{Ti}_{25} \mathrm{Zr}_{25}$ [55], $\mathrm{CoCrFeNiNb} 0.5$ [56], $\mathrm{Zr}_{0.6} \mathrm{CoCrFeNi}_{2.0}$ [57], $\mathrm{Nb}_{0.74} \mathrm{CoCrFeNi}_{2.0}$ [57], $\mathrm{Hf}_{0.55} \mathrm{CoCrFeNi}_{2.0}$ [57], $\mathrm{Ta}_{0.65} \mathrm{CoCrFeNi}_{2.0}$ [57], and $\mathrm{CoCrFeNiTa}{ }_{0.75}$ [58]. Eutectic microstructures obtained in these systems consisted of FCC and BCC phases [48-50,59-61], FCC and Laves phases [62-67], and BCC and B2 phases [68,69]. Developing a eutectic microstructure is relatively easy in conventional alloys due to the availability of experimental and calculated phase diagrams [70-72]. The absence of multicomponent phase diagrams and lack of experimental efforts required for their determination make designing eutectic high-entropy alloys a very challenging task.

The present study was aimed at the development of a eutectic HEA consisting of finely distributed fcc and intermetallic phases in order to obtain an extraordinary combination of strength and ductility. CoCrFeNi is one of the well-studied FCC HEA systems and was shortlisted for the present study. Mo was selected for the development of EHEAs, as its addition to some of the constituent elements of the selected HEA system has been reported to cause precipitation of intermetallic phases and cause a eutectic reaction. The $\mathrm{CoCrFeNi}$-Mo phase diagram has been calculated with the help of Thermo-Calc software (TCHEA database, Thermo-Calc Software AB, Stockholm, Sweden), the verification of which was carried out by performing some experiments. Eutectic HEAs consisting of FCC and intermetallic phases have been successfully developed, and the effect of the developed eutectic mixture on the mechanical properties of the studied alloys has been evaluated.

\section{Experimental Techniques}

Pure element pellets (Fe: 99.95\%, Cr: 99.95\%, Co: 99.95\%, Ni: 99.95\% and Mo: 99.95\%) were used as raw materials, and buttons of high-entropy alloys were prepared by arc melting under argon atmosphere in a water-cooled copper hearth. A vacuum of $10^{-5} \mathrm{mbar}$ was created prior to the insertion of pure argon, and Ti getter was melted for $1 \mathrm{~min}$ to absorb any traces of oxygen prior to the melting of high-entropy alloys. Samples were remelted 5 times and flipped over after each melting to ensure chemical uniformity. Crystal 
structure characterization of the developed alloys was carried out with the help of XRD (STOE, Darmstadt, Germany $\mathrm{Cu} \mathrm{K} \alpha$ radiation, Generator: $20 \mathrm{kV}, 5 \mathrm{~mA}$, step size: $0.04^{\circ}$, Time/step: $1 \mathrm{~s}$ ), which helped in identification of the constituent phases. Microstructural characterization of the developed alloys was carried out with the help of scanning electron microscope (JEOL JSM 6490LA, Tokyo, Japan). The effect of microstructural changes on the mechanical properties of developed alloys was evaluated with the help of Vickers hardness tests and compression tests. A load of $300 \mathrm{~N}$ was applied for $15 \mathrm{~s}$ and a minimum of 8 indents were made to measure the hardness of each sample. Rectangular samples of $3 \mathrm{~mm} \times 3 \mathrm{~mm} \times 7 \mathrm{~mm}$ were taken out from the alloy buttons with the help of a wire electric discharge machine (EDM) (Jiangsu sanxing machinery manufacture company, Taizhou, China) for compression tests. Samples were polished in order to remove EDM wire-cutting marks, and compression testing was performed on a universal testing machine (Shimadzu, Kyoto, Japan) at a strain rate of $1 \times 10^{-3} / \mathrm{s}$.

\section{Results and Discussion}

The prediction of a eutectic reaction in a five-component system using the hit and trial method can be a very tedious and time-consuming task. Thermodynamic calculations/predictions, in this regard, can provide a good starting point. The Calphad method was employed in the present study, and a pseudo-binary phase diagram of the $\mathrm{CoCrFeNi}$ Mo system was calculated with the help of Thermo-Calc software utilizing the TCHEA database. The calculated pseudo-binary phase diagram of the aforementioned high-entropy alloy system is shown in Figure 1.

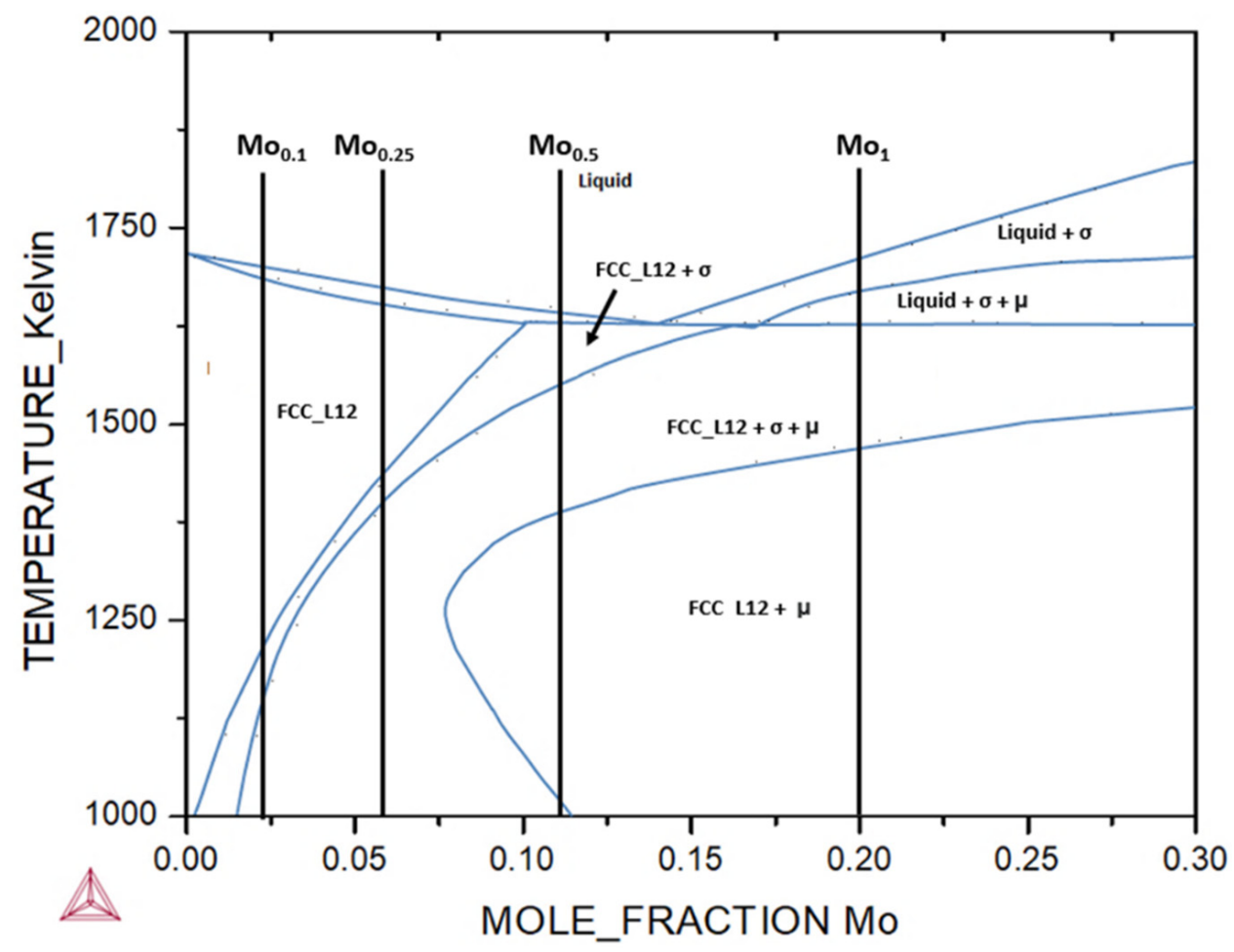

Figure 1. Pseudo-binary phase diagram of CoCrFeNi-Mo system.

The calculated phase diagram, shown in Figure 1, predicted the presence of a eutectic reaction, pointing to the possibility of obtaining a eutectic mixture of fcc and $\sigma$ phase that could help in reducing the strength-ductility tradeoff and obtaining a better combination of mechanical properties. In order to experimentally validate the possibility of a eutectic reaction in the studied system and study its effect on the mechanical properties, different alloy compositions were prepared. The exact compositions of alloys shortlisted for the 
present study are given in Table 1 and are also superimposed on the calculated phase diagram in Figure 1.

Table 1. Composition of selected HEAs.

\begin{tabular}{|c|c|c|c|c|c|c|c|c|c|c|}
\hline \multirow{3}{*}{ Name of Alloy } & \multicolumn{10}{|c|}{ Composition of the Alloy } \\
\hline & \multicolumn{2}{|c|}{ Co } & \multicolumn{2}{|c|}{$\mathrm{Cr}$} & \multicolumn{2}{|c|}{$\mathrm{Fe}$} & \multicolumn{2}{|c|}{$\mathrm{Ni}$} & \multicolumn{2}{|c|}{ Mo } \\
\hline & $\mathbf{x}_{\mathbf{i}}$ & wt.\% & $\mathbf{x}_{\mathbf{i}}$ & wt. $\%$ & $\mathbf{x}_{\mathbf{i}}$ & wt. $\%$ & $\mathbf{x}_{\mathbf{i}}$ & wt.\% & $\mathbf{x}_{\mathbf{i}}$ & wt. \% \\
\hline $\mathrm{CoCrFeNiMo}_{0.1}$ & 0.244 & 25.1 & 0.244 & 22.1 & 0.244 & 23.8 & 0.244 & 25 & 0.024 & 4.0 \\
\hline $\mathrm{CoCrFeNiMo}_{0.25}$ & 0.235 & 23.6 & 0.235 & 20.8 & 0.235 & 22.3 & 0.235 & 23.5 & 0.059 & 9.8 \\
\hline $\mathrm{CoCrFeNiMo}_{0.5}$ & 0.222 & 21.6 & 0.222 & 19.0 & 0.222 & 20.5 & 0.222 & 21.5 & 0.110 & 17.4 \\
\hline $\mathrm{CoCrFeNiMo}_{1.0}$ & 0.200 & 18.3 & 0.200 & 16.2 & 0.200 & 17.4 & 0.200 & 18.3 & 0.200 & 29.8 \\
\hline
\end{tabular}

XRD measurements were carried out in order to identify the phases present in the developed alloy compositions. A comparison of the XRD patterns of the developed $\mathrm{CoCrFeNiMo}_{x}(\mathrm{x}=0.1,0.25,0.5,1.0)$ HEAs is shown in Figure 2. XRD analysis revealed the presence of a single-phase FCC in the $\mathrm{CoCrFeNiMo}{ }_{0.1}$ and $\mathrm{CoCrFeNiMo} .25$ high-entropy alloys. In comparison to the $\mathrm{CoCrFeNiMo}{ }_{0.1}$, the XRD pattern for $\mathrm{CoCrFeNiMo} 0.25$ showed a slight shift towards the left, indicating an increase in the lattice parameters of the FCC phase due to the presence of higher amounts of a large atomic-size element (Mo) in the crystal structure. FCC also appeared as the major phase in the XRD analysis of $\mathrm{CoCrFeNiMo} 0.5$ and $\mathrm{CoCrFeNiMo}{ }_{1.0}$, whereas the presence of a small quantity of intermetallic phases ( $\sigma$ and $\mu$ ) was also observed. The relative quantity of the $\sigma$ phase in $\mathrm{CoCrFeNiMo}_{1.0}$ was higher than that of the $\mu$ phase. Peaks corresponding to both intermetallic phases became more prominent in comparison to the FCC phase with increasing amounts of Mo, thereby indicating increased stability of intermetallic phases and decreased stability of the FCC phase with increasing amounts of Mo in the CoCrFeNi HEA.

A microstructural investigation of the studied samples was carried out with the help of a scanning electron microscope. SEM images of the developed HEA compositions are shown in Figure 3. SEM micrographs of $\mathrm{CoCrFeNiMo}_{0.1}$ and $\mathrm{CoCrFeNiMo} \mathrm{O}_{0.25}$ highentropy alloys, shown in Figure $3 a, b$, respectively, confirmed the presence of the singlephase microstructure, which was identified as the FCC phase from the XRD analysis (shown in Figure 2), while no evidence of eutectic transformation was found in these two alloy compositions. The microstructure changed from cellular for $\mathrm{CoCrFeNiMo} \mathrm{O}_{0.25}$ to

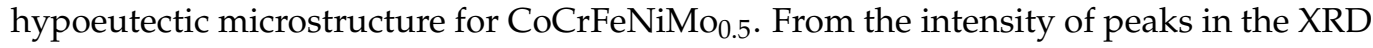
pattern and the amount of phases in the SEM images, it was concluded that dark gray areas in the SEM images (Figure 3) corresponded to the pro-eutectic FCC phase, whereas light gray areas corresponded to the eutectic microstructure of the FCC and intermetallic phases. The amount of eutectic mixture evidenced in $\mathrm{CoCrFeNiMo} \mathrm{O}_{0.5}$ was very small, and that, too, was found at the grain boundaries. A large increase in the amount of Mo was made, and $\mathrm{CoCrFeNiMo} \mathrm{H}_{1.0}$ was developed in a search for the complete eutectic composition. SEM images of CoCrFeNiMo ${ }_{1.0}$ are shown in Figure $3 \mathrm{~d}$. As shown in the Figure, the microstructure of $\mathrm{CoCrFeNiMo}{ }_{1.0}$ showed the presence of relatively high volume fraction of the eutectic lamellar mixture in comparison to $\mathrm{CoCrFeNiMo} 0.5$, whereas a relative decrease in the amount of dendrites corresponding to the pro-eutectic FCC phase, was evidenced. It is evident from Figure $3 c, d$ that the volume fraction of the eutectic lamellar microstructure increased with the increase in Mo content. 


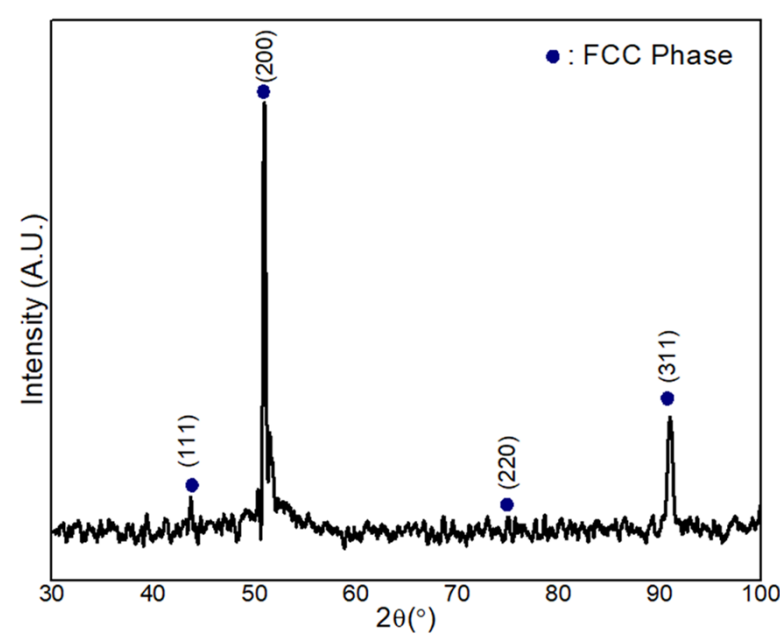

(a)

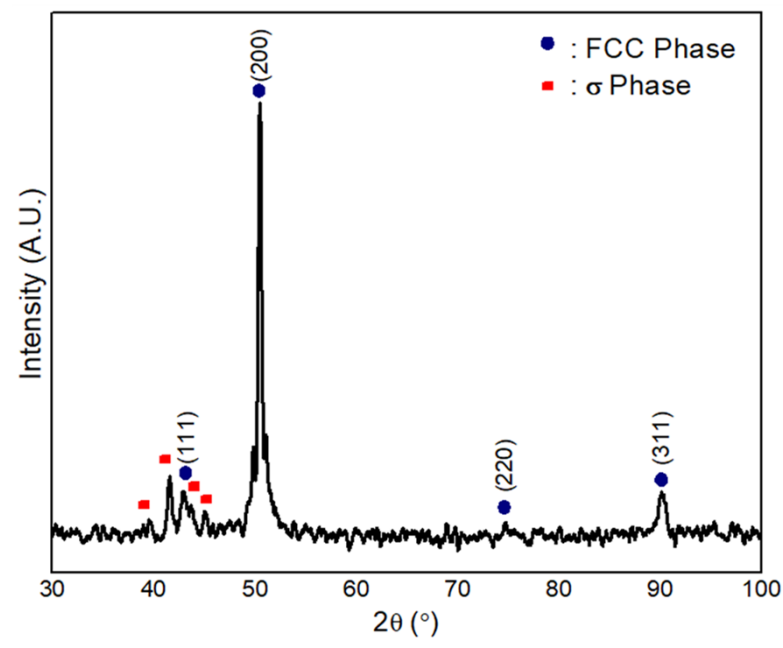

(c)

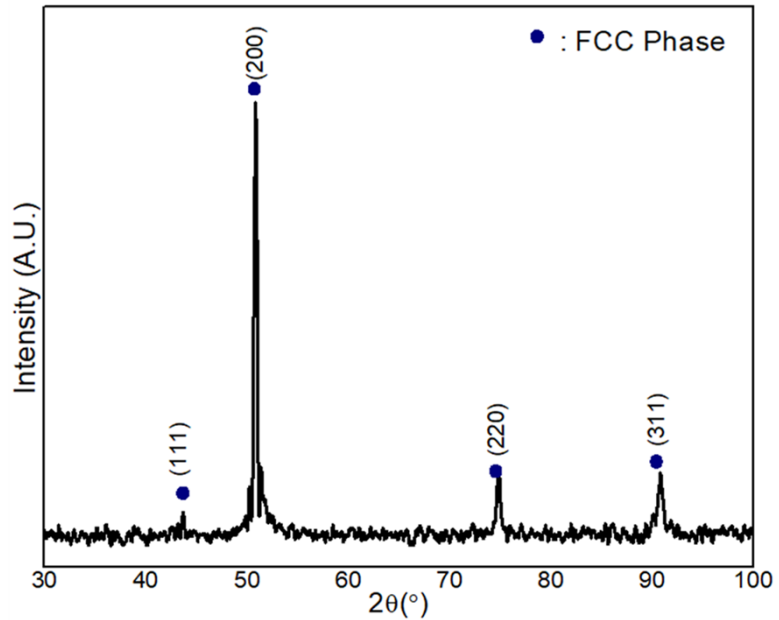

(b)

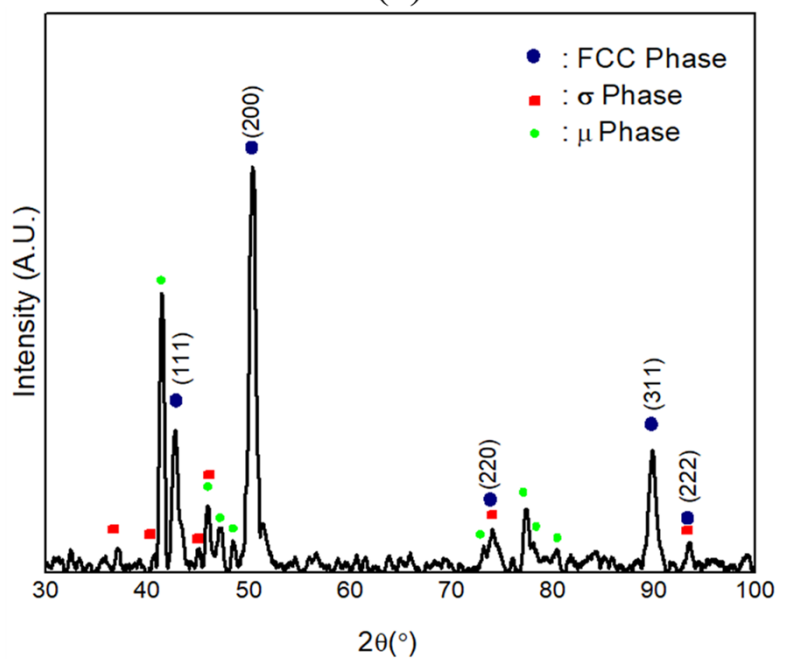

(d)

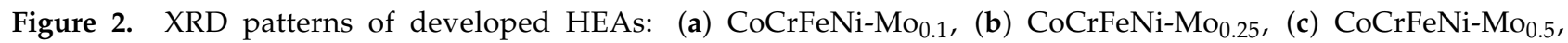
(d) $\mathrm{CoCrFeNi}-\mathrm{Mo}_{1.0}$.

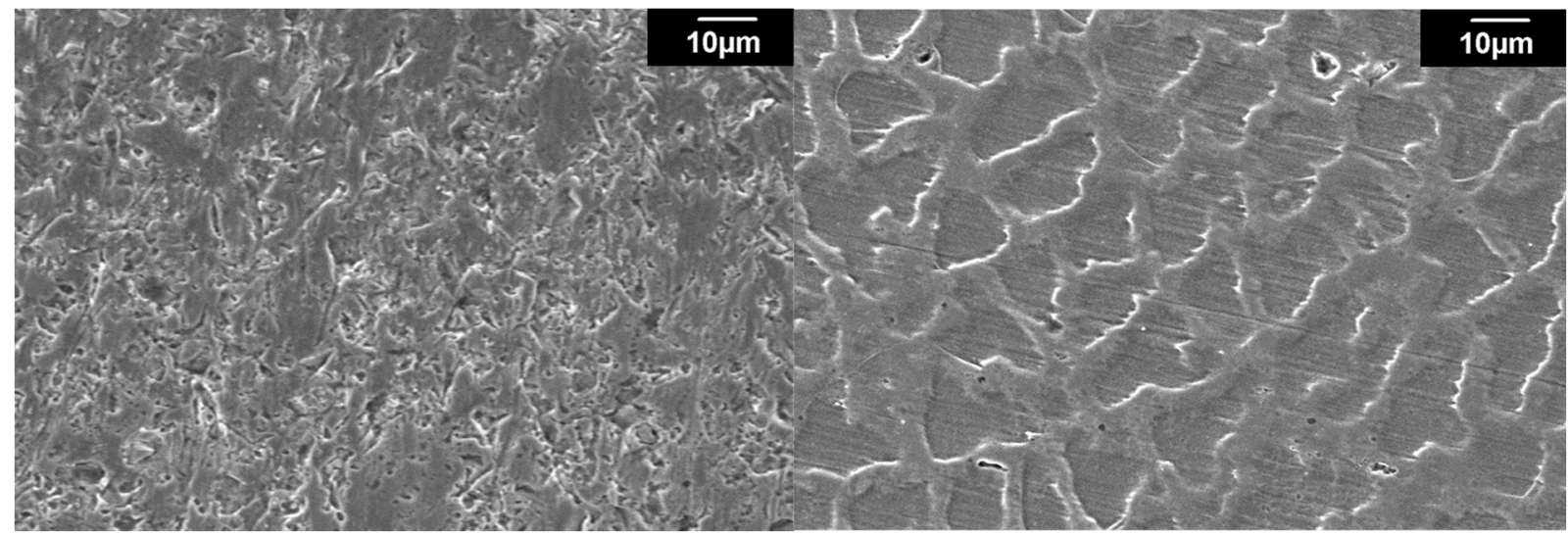

(a) (b)

Figure 3. Cont. 


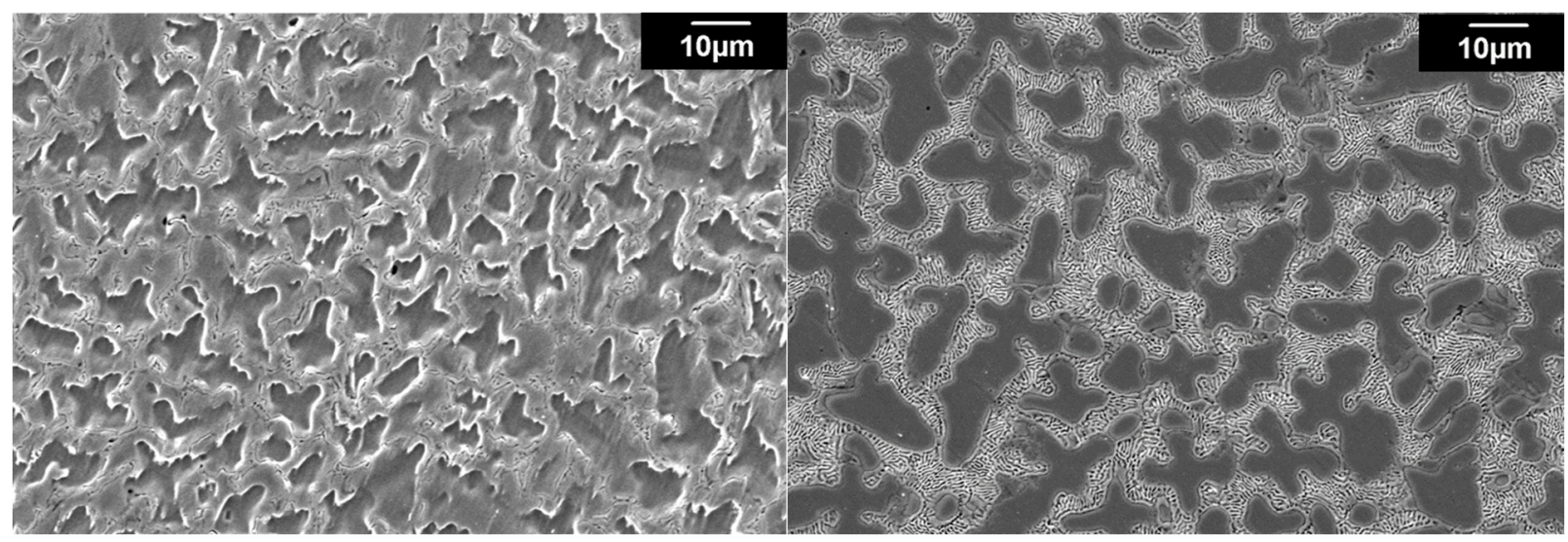

(c)

(d)

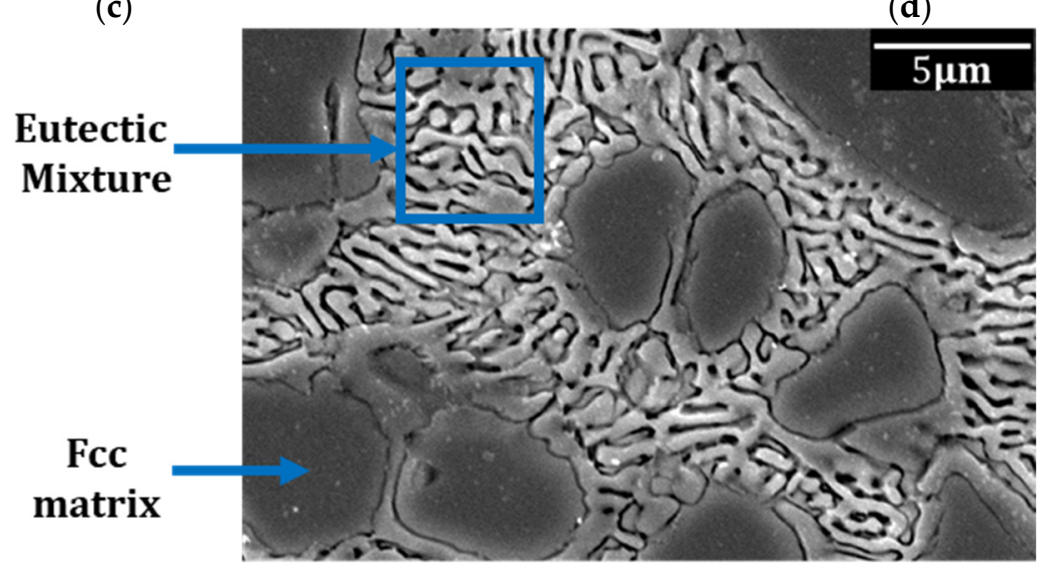

(e)

Figure 3. Scanning electron micrographs of developed HEAs: (a) $\mathrm{CoCrFeNi}-\mathrm{Mo}_{0.1}$, (b) $\mathrm{CoCrFeNi}^{-\mathrm{Mo}_{0.25}}$, (c) $\mathrm{CoCrFeNi} \mathrm{Mo}{ }_{0.5}$, (d) $\mathrm{CoCrFeNi}-\mathrm{Mo}_{1.0}$, (e) $\mathrm{CoCrFeNi}-\mathrm{Mo}_{1.0}$ (higher magnification).

A comparison of the SEM and XRD results obtained during the present study with the calculated phase diagrams showed some deviations. The calculated pseudo-binary phase diagram predicted the $\mathrm{CoCrFeNiMo} \mathrm{C}_{0.1}$ and $\mathrm{CoCrFeNiMo}_{0.25}$ alloys as non-eutectic threephase $(\mathrm{FCC}+\sigma+\mu)$ alloys at room temperature. The SEM and XRD analyses carried out during the present study confirmed them as non-eutectic alloy compositions, but they were found to be single-phase fcc alloys. It can be safely concluded that the calculated pseudobinary phase diagram of the CoCrFeNi-Mo HEA system underestimated the composition range of the single-phase FCC region, as it should be on the right of $\mathrm{CoCrFeNiMo} \mathrm{Mo}_{0.25}$. The experimental results of $\mathrm{CoCrFeNiMo} \mathrm{Co}_{0.5}$ showed the presence of three phases $(\mathrm{FCC}+\sigma+\mu)$ in the microstructure, whereas the amount of eutectic mixture in this composition was small and at the grain boundaries, thereby indicating that this composition was to the right of, but close to, the boundary of the FCC phase. The calculated phase diagram contained a threephase mixture (FCC, $\sigma$, and $\mu$ ) for the $\mathrm{CoCrFeNiMo}_{0.5}$ and $\mathrm{CoCrFeNiMo}_{1.0}$ compositions at high temperatures and a two-phase mixture (FCC and $\mu$ ) at low temperatures. However, the experimental results obtained for these as-cast compositions showed the presence of three phases (FCC, $\sigma$, and $\mu$ ) which as per the calculated phase diagrams, corresponded to the high temperature microstructures of these compositions. The presence of these phases at room temperature can be associated with the sluggish diffusion kinetics generally attributed to high-entropy alloys. Moreover, the calculated pseudo-binary phase diagram predicted a eutectic reaction in the center of the $\mathrm{CoCrFeNiMo}_{0.5}$ and $\mathrm{CoCrFeNiMo}_{1.0}$ compositions, whereas the experimental results obtained even for $\mathrm{CoCrFeNiMo}_{1.0}$ showed the presence of a hypo-eutectic microstructure. Thus, it can be concluded that the calculated phase diagram showed a eutectic reaction at lower amounts of Mo while the actual eutectic reaction was to the right side of even $\mathrm{CoCrFeNiMo}_{1.0}$. Based on the above discussion, 
some changes in the pseudo-binary diagram of the CoCrFeNi-Mo system are proposed, as shown in Figure 4.

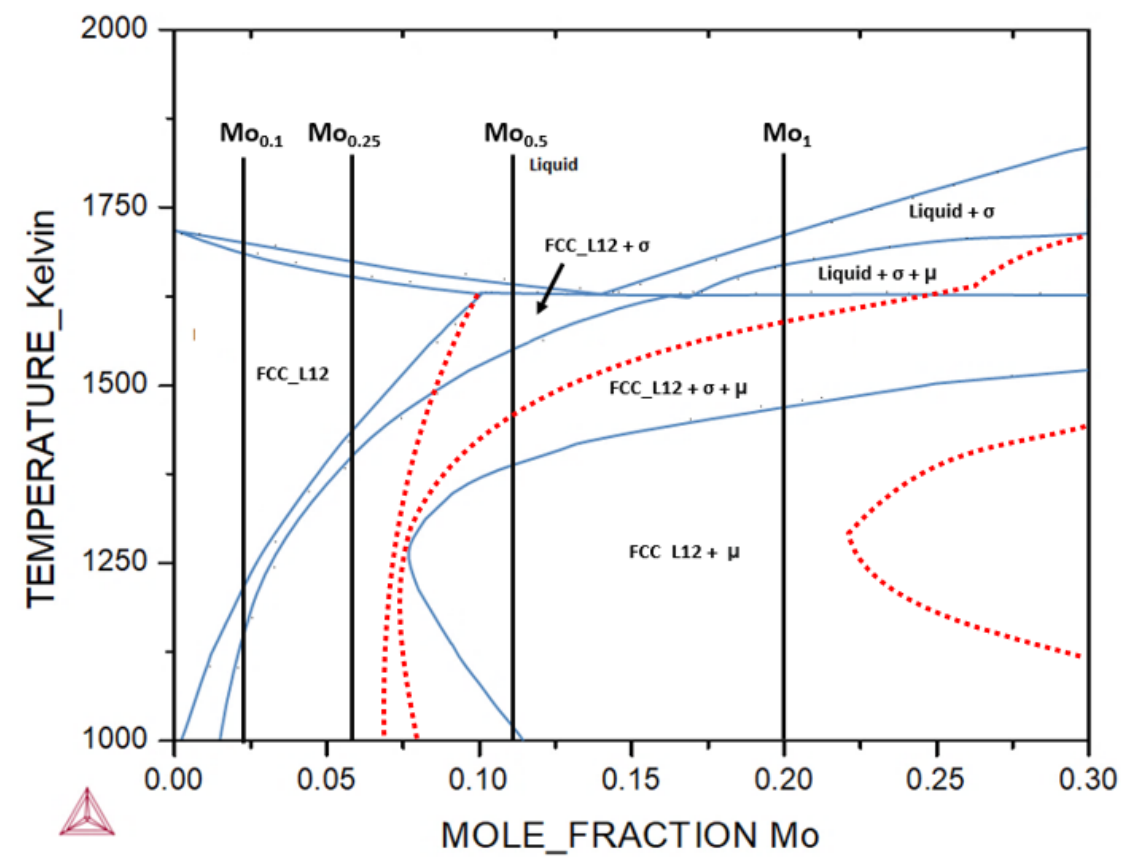

Figure 4. Modified pseudo-binary phase diagram of CoCrFeNi-Mo system.

The effect of microstructural changes in CoCrFeNi caused by the addition of Mo on its mechanical properties was evaluated by performing Vickers hardness and compression tests. Hardness results for different samples are shown in Figure 5a, while compression test results are shown in Figure $5 \mathrm{~b}$. CoCrFeNiMo $\mathrm{Co}_{0.1}$ showed a hardness of around $150.4 \mathrm{HV}$. A slight increase in the hardness was evidenced on increasing the amount of Mo from $\mathrm{CoCrFeNiMo}_{0.1}$ to $\mathrm{CoCrFeNiMo}_{0.25}$. This small increase in hardness can be attributed to solid solution strengthening as both of these alloys showed the presence of a single-phase FCC microstructure. Increasing the amount of Mo to CoCrFeNiMo 0.25 increased the solid solution strengthening, thereby causing a small increase in hardness. As the Mo content increased further, the value of hardness jumped to $257.5 \mathrm{HV}$ for $\mathrm{CoCrFeNiMo} \mathrm{Co}_{0.5}$ and to $425.5 \mathrm{HV}$ for $\mathrm{CoCrFeNiMo}_{1.0}$. This steep change in the slope of the hardness curve was in line with the microstructural changes, as both of these alloys manifested a eutectic microstructure consisting of hard intermetallic compounds (hard $\sigma$ and $\mu$ ) along with the FCC phase. It can be concluded that the hardness of the developed HEA can be increased by increasing the volume fraction of the $\sigma$ and $\mu$ phases.

In addition to the hardness test, the effect of microstructural changes on the mechanical properties of the studied HEA system was evaluated with the help of compression testing. Results of the compression tests of the studied samples are shown in Figure 5b, whereas the variation in yield strength as a function of increasing amounts of Mo is shown in Figure 5c. As shown in Figure 5b,c, CoCrFeNiMo 0.1 and $\mathrm{CoCrFeNiMo}_{0.25}$ alloys showed closely similar values for yield strength and ductility. This was because they both had a single-phase FCC structure. The value for the yield strength of $\mathrm{CoCrFeNiMo}_{0.25}$ was a little higher than that of $\mathrm{CoCrFeNiMo}{ }_{0.1}$, which could be attributed to the increase in solid solution strengthening due to the increased amount of Mo in the solid solution. The values for the yield strengths of $\mathrm{CoCrFeNiMo}_{0.5}$ and $\mathrm{CoCrFeNiMo}_{1.0}$ were found to be considerably higher than those of the $\mathrm{CoCrFeNiMo}_{0.1}$ and $\mathrm{CoCrFeNiMo}_{0.25}$ alloys. This significant increase in the hardness in these samples has been attributed to the presence of fine-grained eutectic microstructures that consisted of hard intermetallic phases along with a soft FCC phase. The fine distribution of the hard and soft phases as a result of eutectic reaction helped in obtaining significantly higher values for yield strengths. The alloy 
$\mathrm{CoCrFeNiMo}_{1.0}$ showed the highest value for yield strength due to the increased amount of intermetallic phases; however, increase in the amount of intermetallic phases also caused decreases in its ductility. Machine displacement was used for strain measurements due to the size of the compression test samples, and it might have involved some contribution from sample slippage. The strain data are therefore reliable only for qualitative analysis. It can be seen from the hardness as well as from the compression test results that the introduction of a small amount of Mo in the CoCrFeNi HEA did not change its constituent phases, and the microstructure of $\mathrm{CoCrFeNiMo}_{0.1}$ and $\mathrm{CoCrFeNiMo}{ }_{0.25}$ consisted of a single-phase FCC. The introduction of Mo in the same FCC lattice caused lattice distortion, thereby leading to solid solution strengthening that resulted in a slight increase in the hardness as well as the yield strength. Further increases in the amount of Mo changed phase stability and the solidification path. Crystal structure and microstructural characterization of $\mathrm{CoCrFeNiMo}_{0.5}$ and $\mathrm{CoCrFeNiMo}{ }_{1.0}$ confirmed the development of eutectic microstructure (consisting of finely distributed fcc and intermetallic phase) in the studied HEA system. As a result, significant increases in hardness and yield strength were evidenced. Thus, it was concluded that development of eutectic high-entropy alloys consisting of finely distributed hard and tough phases can help in achieving a far superior combination of mechanical properties in comparison to their HEA counterparts, in addition to improving their castability $[46,47,50]$.

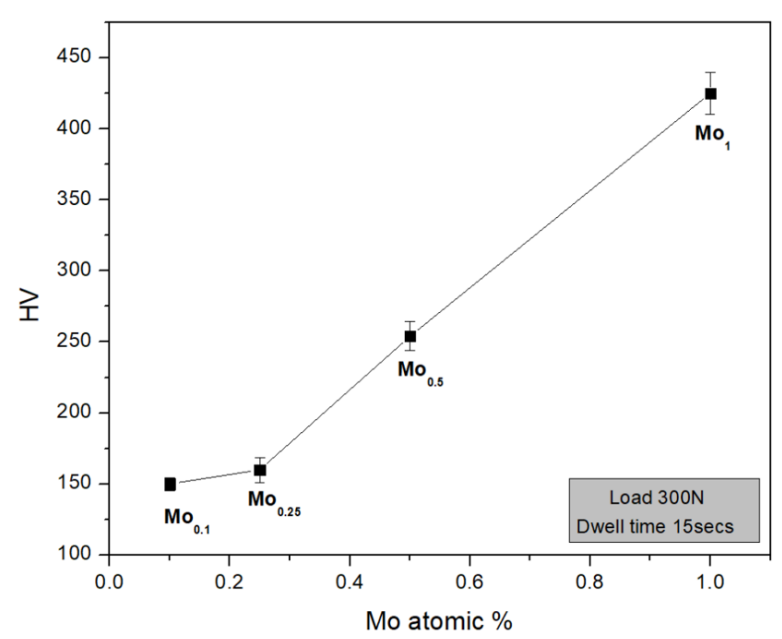

(a)

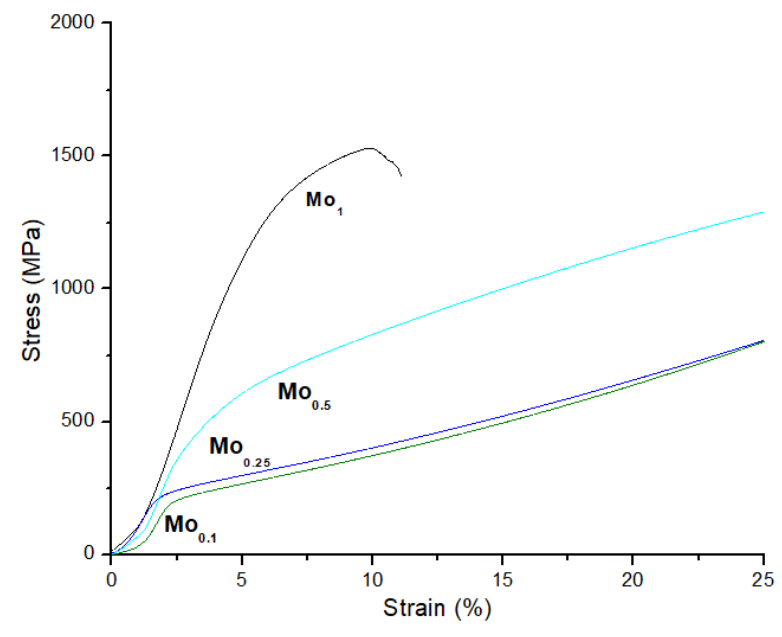

(b)

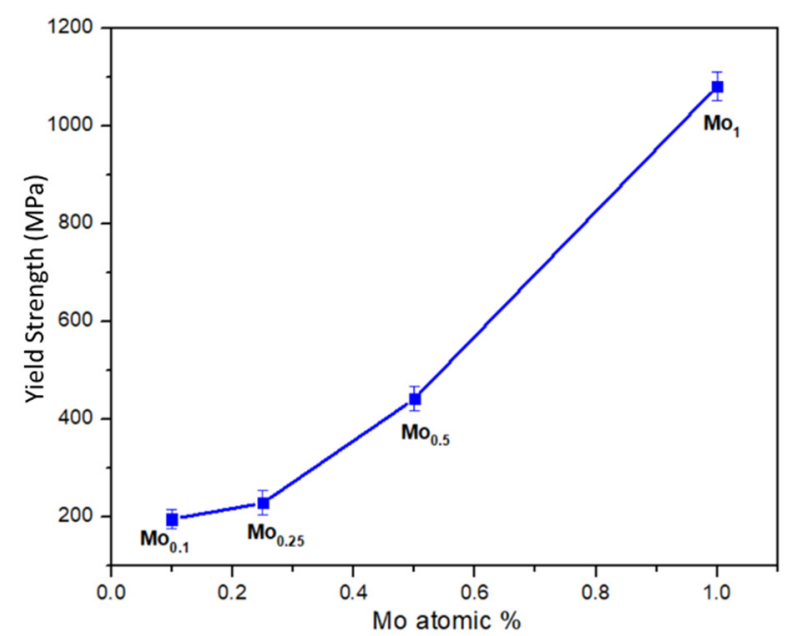

(c)

Figure 5. (a) Variation of hardness as a function of amount of Mo in the CoCrFeNiMo $\mathrm{HEA}$; (b) compression testing results for the studied $\mathrm{CoCrFeNiMo}_{\mathrm{x}}$ alloys; (c) variation of yield strength as a function of amount of Mo in the $\mathrm{CoCrFeNiMo}_{\mathrm{x}} \mathrm{HEA}$. 
The CoCrFeNiMo HEA system has also been partially investigated in a previous study [73]. They reported the presence of an fcc phase in $\mathrm{CoCrFeNi} \mathrm{HEA}$ and $\mathrm{CoCrFeNiMo} \mathrm{O}_{0.3}$ HEA, whereas the presence of a two-phase microstructure $(F C C+\sigma)$ and three-phase microstructure (FCC $+\sigma+\mu$ ) was evidenced in the $\mathrm{CoCrFeNiMo} 0.5$ and $\mathrm{CoCrFeNiMo} \mathrm{No}_{0.85}$ HEAs, respectively. Crystal structure findings of this study [73] were found to be in agreement with the experimental results and predictions of thermodynamic calculations carried out in the present study. Shun et al. [73] did not report the presence of eutectic microstructure in the $\mathrm{CoCrFeNiMo}_{0.5}$ and $\mathrm{CoCrFeNiMo}_{0.85}$ HEAs, whereas the presence of eutectic microstructure was clearly evidenced in the $\mathrm{CoCrFeNiMo}$..5 and $\mathrm{CoCrFeNiMo}$ HEAs prepared during the present study. The presence of eutectic microstructure in these compositions was also predicted by the pseudo-binary phase diagram calculated during the present study with the help of Thermo-Calc using the TCHEA database. Difference in the microstructure between the two studies could be attributed to the purity of starting components. The raw materials used in the present study were $99.95 \%$ pure, whereas those used in the previous study were $99 \%$ pure. The purity of starting components can greatly affect the solidification path, especially in multicomponent systems such as HEA, and be responsible for changes in the microstructure. The yield strength of $\mathrm{CoCrFeNiMo} 0.5$ (the only common HEA in the two studies) was found to be similar ( 510 MPa).

Designing eutectic HEAs has been a tedious and time-consuming task. Empirical and semi-empirical methods based on thermodynamic variables (such as valence electron configuration, atomic size difference, entropy of mixing, electronegativity difference, and enthalpy of mixing) were previously used for estimating phase stability in HEAs and for designing EHEAs. The accuracy of these simple formulas may not be very high due to the complex interactions in multicomponent systems, and even in the best-case scenario, these formulas could only predict phase stability in a specific composition. Systematic alloy design and microstructure modification may not be possible. In the present study, it has been shown that calculated phase diagrams can serve as a very good starting point to evaluate the possibility of obtaining eutectic microstructure in a selected HEA system and for the systematic investigation of eutectic HEAs. The amount of experimental effort required to design hypo eutectic, complete eutectic, and hyper eutectic alloys can be significantly reduced. The pseudo-binary phase diagrams calculated during the present study required slight adjustments, and that, too, was possible by carrying out the microstructural and crystal structural characterization of a few samples. Some deviations from the calculated phase diagrams were expected, as the developed HEAs were studied in the as-cast state and were not in complete thermodynamic equilibrium. Despite these small deviations, the accuracy of calculated phase diagrams is quite high and can be attributed to the significant evolution of thermodynamic models and thermodynamic descriptions constituting lowerorder systems over the last few decades [74,75]. It is believed that calculated pseudo-binary phase diagrams hold great potential not only in aiding exploration of HEA and EHEA systems but also in facilitating the design of non-equiatomic HEAs.

\section{Conclusions}

A pseudo-binary phase diagram of the CoCrFeNi-Mo system was successfully calculated with the help of the Thermo-Calc software package using the TCHEA database. The calculated phase diagram pointed to the possibility of developing eutectic microstructure in the selected HEA system, which was also experimentally validated.

Characterization results of the developed alloys were found to be similar to those predicted by the calculated pseudo-binary phase diagram. Some changes in the calculated phase diagram have been proposed in light of the obtained experimental results. Comparison of experimental and calculated results revealed that calculated pseudo-binary phase diagrams can serve as a very good starting point for the design and development of EHEAs and, as a result, experimental efforts required in this regard can be significantly reduced.

Single-phase FCC high-entropy alloys $\left(\mathrm{CoCrFeNiMo}_{0.1}\right.$ and $\left.\mathrm{CoCrFeNiMo}{ }_{0.25}\right)$ and eutectic high-entropy alloys $\left(\mathrm{CoCrFeNiMo}{ }_{0.5}\right.$ and $\left.\mathrm{CoCrFeNiMo}{ }_{1.0}\right)$ were successfully developed. 
The addition of small amounts of $\mathrm{Mo}\left(\mathrm{CoCrFeNiMo} \mathrm{Co}_{0.1}\right.$ and $\left.\mathrm{CoCrFeNiMo}{ }_{0.25}\right)$ caused solid solution strengthening, and a small increase in the hardness and yield strength was also evidenced. A significant increase in the hardness and yield strength was confirmed by the development of eutectic morphology in the microstructure. As a result, hardness of the samples increased from $150 \mathrm{HV}$ for $\mathrm{CoCrFeNiMo} \mathrm{Co}_{0.1}$ to $425.5 \mathrm{HV}$ for $\mathrm{CoCrFeNiMo}_{1.0}$, whereas yield strength increased from around $218 \mathrm{MPa}$ for $\mathrm{CoCrFeNiMo}_{0.1}$ to around $1100 \mathrm{MPa}$ for CoCrFeNiMo1.0. No fractures were evidenced during the compression tests of $\mathrm{CoCrFeNiMo}_{0.1}, \mathrm{CoCrFeNiMo}_{0.25}$, and $\mathrm{CoCrFeNiMo}_{0.5}$ alloys, which provided a far superior combination of strength and ductility in comparison to the parent HEA. A decrease in the toughness observed in the CoCrFeNiMo 1.0 allow was attributed to the increased amount of intermetallic phases in the microstructure.

\begin{abstract}
Author Contributions: Conceptualization, K.Y.; methodology, M.M. (Muhammad Mukarram); software, K.Y.; validation, M.M. (Muhammad Mukarram); formal analysis, M.M. (Mohammad Mujahid); investigation, M.M. (Mohammad Mujahid); writing—original draft preparation, M.A.M.; writingreview and editing, M.A.M. and K.Y.; supervision, K.Y. All authors have read and agreed to the published version of the manuscript.
\end{abstract}

Funding: Financial support from the Higher Education Commission of Pakistan (HEC-NRPU Project \# 6019) is acknowledged.

Institutional Review Board Statement: Not applicable.

Informed Consent Statement: Not applicable.

Data Availability Statement: Not applicable.

Conflicts of Interest: The authors declare that they have no known competing financial interests or personal relationships that could have appeared to influence the work reported in this paper.

\title{
References
}

1. Nakai, M.; Eto, T. New aspect of development of high strength aluminum alloys for aerospace applications. Mater. Sci. Eng. A 2000, 285, 62-68. [CrossRef]

2. Zhu, L.; Ruan, H.; Chen, A.; Guo, X.; Lu, J. Microstructures-based constitutive analysis for mechanical properties of gradientnanostructured 304 stainless steels. Acta Mater. 2017, 128, 375-390. [CrossRef]

3. Wu, X.L.; Yang, M.X.; Yuan, F.P.; Chen, L.; Zhu, Y.T. Combining gradient structure and TRIP effect to produce austenite stainless steel with high strength and ductility. Acta Mater. 2016, 112, 337-346. [CrossRef]

4. Yan, F.K.; Liu, G.Z.; Tao, N.R.; Lu, K. Strength and ductility of 316L austenitic stainless steel strengthened by nano-scale twin bundles. Acta Mater. 2012, 60, 1059-1071. [CrossRef]

5. Zheng, Z.B.; Zheng, Y.G. Effects of surface treatments on the corrosion and erosion-corrosion of 304 stainless steel in $3.5 \% \mathrm{NaCl}$ solution. Corros. Sci. 2016, 112, 657-668. [CrossRef]

6. Shan, C.X.; Hou, X.; Choy, K.-L. Corrosion resistance of TiO2 films grown on stainless steel by atomic layer deposition. Surf. Coat. Technol. 2008, 202, 2399-2402. [CrossRef]

7. Bilal, M.M.; Yaqoob, K.; Zahid, M.H.; Tanveer, W.H.; Wadood, A.; Ahmed, B. Effect of austempering conditions on the microstructure and mechanical properties of AISI 4340 and AISI 4140 steels. J. Mater. Res. Technol. 2019, 8, 5194-5200. [CrossRef]

8. Hegele, P.; von Kobylinski, J.; Hitzler, L.; Krempaszky, C.; Werner, E. In-Situ XRD Study of Phase Transformation Kinetics in a Co-Cr-W-Alloy Manufactured by Laser Powder-Bed Fusion. Eksploat. Niezawodn. Maint. Reliab. 2021, 11, 176.

9. Walczak, M.; Pieniak, D.; Niewczas, A.M. Effect of recasting on the useful properties CoCrMoW alloy. Eksploat. Niezawodn. Maint. Reliab. 2014, 16, 330-336.

10. Szala, M.; Chocyk, D.; Skic, A.; Kamiński, M.; Macek, W.; Turek, M. Effect of Nitrogen Ion Implantation on the Cavitation Erosion Resistance and Cobalt-Based Solid Solution Phase Transformations of HIPed Stellite 6. Materials 2021, 14, 2324. [CrossRef]

11. Féron, D. 2-Overview of nuclear materials and nuclear corrosion science and engineering. In Nuclear Corrosion Science and Engineering; Féron, D., Ed.; Woodhead Publishing: Sawston, UK, 2012; pp. 31-56. [CrossRef]

12. Griffiths, M. Chapter 9-Ni-Based Alloys for Reactor Internals and Steam Generator Applications. In Structural Alloys for Nuclear Energy Applications; Odette, G.R., Zinkle, S.J., Eds.; Elsevier: Boston, MA, USA, 2019; pp. 349-409. [CrossRef]

13. Yeh, J.W.; Chen, S.K.; Lin, S.J.; Gan, J.Y.; Chin, T.S.; Shun, T.T.; Tsau, C.H.; Chang, S.Y. Nanostructured High-Entropy Alloys with Multiple Principal Elements: Novel Alloy Design Concepts and Outcomes. Adv. Eng. Mater. 2004, 6, 299-303. [CrossRef]

14. Cantor, B.; Chang, I.T.H.; Knight, P.; Vincent, A.J.B. Microstructural development in equiatomic multicomponent alloys. Mater. Sci. Eng. A 2004, 375, 213-218. [CrossRef]

15. Tsai, M.-H.; Yeh, J.-W. High-Entropy Alloys: A Critical Review. Mater. Res. Lett. 2014, 2, 107-123. [CrossRef] 
16. Fu, Z.; Chen, W.; Wen, H.; Zhang, D.; Chen, Z.; Zheng, B.; Zhou, Y.; Lavernia, E.J. Microstructure and strengthening mechanisms in an FCC structured single-phase nanocrystalline Co25Ni25Fe25Al7.5Cu17.5 high-entropy alloy. Acta Mater. 2016, $107,59-71$. [CrossRef]

17. Gludovatz, B.; Hohenwarter, A.; Catoor, D.; Chang, E.H.; George, E.P.; Ritchie, R.O. A fracture-resistant high-entropy alloy for cryogenic applications. Science 2014, 345, 1153-1158. [CrossRef] [PubMed]

18. Senkov, O.N.; Wilks, G.B.; Scott, J.M.; Miracle, D.B. Mechanical properties of Nb25Mo25Ta25W25 and V20Nb20Mo20Ta20W20 refractory high entropy alloys. Intermetallics 2011, 19, 698-706. [CrossRef]

19. Feuerbacher, M.; Lienig, T.; Thomas, C. A single-phase bcc high-entropy alloy in the refractory Zr-Nb-Ti-V-Hf system. Scr. Mater. 2018, 152, 40-43. [CrossRef]

20. Youssef, K.M.; Zaddach, A.J.; Niu, C.; Irving, D.L.; Koch, C.C. A Novel Low-Density, High-Hardness, High-entropy Alloy with Close-packed Single-phase Nanocrystalline Structures. Mater. Res. Lett. 2015, 3, 95-99. [CrossRef]

21. Yusenko, K.V.; Riva, S.; Carvalho, P.A.; Yusenko, M.V.; Arnaboldi, S.; Sukhikh, A.S.; Hanfland, M.; Gromilov, S.A. First hexagonal close packed high-entropy alloy with outstanding stability under extreme conditions and electrocatalytic activity for methanol oxidation. Scr. Mater. 2017, 138, 22-27. [CrossRef]

22. Zhu, C.; Lu, Z.P.; Nieh, T.G. Incipient plasticity and dislocation nucleation of FeCoCrNiMn high-entropy alloy. Acta Mater. 2013, 61, 2993-3001. [CrossRef]

23. Senkov, O.N.; Scott, J.M.; Senkova, S.V.; Miracle, D.B.; Woodward, C.F. Microstructure and room temperature properties of a high-entropy TaNbHfZrTi alloy. J. Alloys Compd. 2011, 509, 6043-6048. [CrossRef]

24. Senkov, O.N.; Wilks, G.B.; Miracle, D.B.; Chuang, C.P.; Liaw, P.K. Refractory high-entropy alloys. Intermetallics 2010, 18, 1758-1765. [CrossRef]

25. Chuang, M.-H.; Tsai, M.-H.; Wang, W.-R.; Lin, S.-J.; Yeh, J.-W. Microstructure and wear behavior of AlxCo1.5CrFeNi1.5Tiy high-entropy alloys. Acta Mater. 2011, 59, 6308-6317. [CrossRef]

26. Hsu, C.-Y.; Sheu, T.-S.; Yeh, J.-W.; Chen, S.-K. Effect of iron content on wear behavior of AlCoCrFexMo0.5Ni high-entropy alloys. Wear 2010, 268, 653-659. [CrossRef]

27. Zhou, N.; Hu, T.; Huang, J.; Luo, J. Stabilization of nanocrystalline alloys at high temperatures via utilizing high-entropy grain boundary complexions. Scr. Mater. 2016, 124, 160-163. [CrossRef]

28. Zou, Y.; Maiti, S.; Steurer, W.; Spolenak, R. Size-dependent plasticity in an $\mathrm{Nb}_{25} \mathrm{Mo}_{25} \mathrm{Ta}_{25} \mathrm{~W}_{25}$ refractory high-entropy alloy. Acta Mater. 2014, 65, 85-97. [CrossRef]

29. Rowthu, S.; Murty, B.; Kottada, R.S. Alloying, thermal stability and strengthening in spark plasma sintered AlxCoCrCuFeNi high entropy alloys. J. Alloys Compd. 2014, 583, 419-426. [CrossRef]

30. Rodriguez, A.A.; Tylczak, J.H.; Gao, M.C.; Jablonski, P.D.; Detrois, M.; Ziomek-Moroz, M.; Hawk, J.A. Effect of Molybdenum on the Corrosion Behavior of High-Entropy Alloys $\mathrm{CoCrFeNi} 2$ and $\mathrm{CoCrFeNi} \mathrm{Mo}_{0.25}$ under Sodium Chloride Aqueous Conditions. Adv. Mater. Sci. Eng. 2018, 2018, 3016304. [CrossRef]

31. Chen, Y.Y.; Hong, U.T.; Shih, H.C.; Yeh, J.W.; Duval, T. Electrochemical kinetics of the high entropy alloys in aqueous environments-A comparison with type 304 stainless steel. Corros. Sci. 2005, 47, 2679-2699. [CrossRef]

32. Chen, Y.Y.; Duval, T.; Hung, U.D.; Yeh, J.W.; Shih, H.C. Microstructure and electrochemical properties of high entropy alloys-A comparison with type-304 stainless steel. Corros. Sci. 2005, 47, 2257-2279. [CrossRef]

33. Lin, C.-M.; Tsai, H.-L. Evolution of microstructure, hardness, and corrosion properties of high-entropy $\mathrm{Al}_{0.5} \mathrm{CoCrFeNi}$ alloy. Intermetallics 2011, 19, 288-294. [CrossRef]

34. Dada, M.; Popoola, P.; Adeosun, S.; Mathe, N. High Entropy Alloys for Aerospace Applications. In Aerodynamics; IntechOpen: London, UK, 2019.

35. Senkov, O.N.; Woodward, C.F. Microstructure and properties of a refractory NbCrMo0.5Ta0.5TiZr alloy. Mater. Sci. Eng. A 2011, 529, 311-320. [CrossRef]

36. Koželj, P.; Vrtnik, S.; Jelen, A.; Jazbec, S.; Jagličić, Z.; Maiti, S.; Feuerbacher, M.; Steurer, W.; Dolinšek, J. Discovery of a Superconducting High-Entropy Alloy. Phys. Rev. Lett. 2014, 113, 107001. [CrossRef]

37. Yuan, Y.; Wu, Y.; Luo, H.; Wang, Z.; Liang, X.; Yang, Z.; Wang, H.; Liu, X.; Lu, Z. Superconducting $\operatorname{Ti}_{15} \mathrm{Zr}_{15} \mathrm{Nb}_{35} \mathrm{Ta}_{35} \mathrm{High} \mathrm{Entropy}$ Alloy With Intermediate Electron-Phonon Coupling. Front. Mater. 2018, 5, 72. [CrossRef]

38. Ayyagari, A.; Salloom, R.; Muskeri, S.; Mukherjee, S. Low activation high entropy alloys for next generation nuclear applications. Materialia 2018, 4, 99-103. [CrossRef]

39. Lu, Y.; Huang, H.; Gao, X.; Ren, C.; Gao, J.; Zhang, H.; Zheng, S.; Jin, Q.; Zhao, Y.; Lu, C.; et al. A promising new class of irradiation tolerant materials: Ti2ZrHfV0.5Mo0.2 high-entropy alloy. J. Mater. Sci. Technol. 2019, 35, 369-373. [CrossRef]

40. Wang, J.; Guo, T.; Li, J.; Jia, W.; Kou, H. Microstructure and mechanical properties of non-equilibrium solidified CoCrFeNi high entropy alloy. Mater. Chem. Phys. 2018, 210, 192-196. [CrossRef]

41. Otto, F.; Dlouhý, A.; Somsen, C.; Bei, H.; Eggeler, G.; George, E.P. The influences of temperature and microstructure on the tensile properties of a CoCrFeMnNi high-entropy alloy. Acta Mater. 2013, 61, 5743-5755. [CrossRef]

42. Wani, I.S.; Bhattacharjee, T.; Sheikh, S.; Bhattacharjee, P.P.; Guo, S.; Tsuji, N. Tailoring nanostructures and mechanical properties of AlCoCrFeNi2.1 eutectic high entropy alloy using thermo-mechanical processing. Mater. Sci. Eng. A 2016, 675, 99-109. [CrossRef]

43. Zhang, Y.; Zuo, T.T.; Tang, Z.; Gao, M.C.; Dahmen, K.A.; Liaw, P.K.; Lu, Z.P. Microstructures and properties of high-entropy alloys. Prog. Mater. Sci. 2014, 61, 1-93. [CrossRef] 
44. Lu, Y.; Gao, X.; Jiang, L.; Chen, Z.; Wang, T.; Jie, J.; Kang, H.; Zhang, Y.; Guo, S.; Ruan, H.; et al. Directly cast bulk eutectic and near-eutectic high entropy alloys with balanced strength and ductility in a wide temperature range. Acta Mater. 2017, 124, 143-150. [CrossRef]

45. Wani, I.S.; Bhattacharjee, T.; Sheikh, S.; Lu, Y.P.; Chatterjee, S.; Bhattacharjee, P.P.; Guo, S.; Tsuji, N. Ultrafine-Grained AlCoCrFeNi2.1 Eutectic High-Entropy Alloy. Mater. Res. Lett. 2016, 4, 174-179. [CrossRef]

46. Zhu, J.M.; Zhang, H.F.; Fu, H.M.; Wang, A.M.; Li, H.; Hu, Z.Q. Microstructures and compressive properties of multicomponent AlCoCrCuFeNiMox alloys. J. Alloys Compd. 2010, 497, 52-56. [CrossRef]

47. Lu, Y.; Dong, Y.; Guo, S.; Jiang, L.; Kang, H.; Wang, T.; Wen, B.; Wang, Z.; Jie, J.; Cao, Z.; et al. A Promising New Class of High-Temperature Alloys: Eutectic High-Entropy Alloys. Sci. Rep. 2014, 4, 6200. [CrossRef]

48. Jin, X.; Bi, J.; Zhang, L.; Zhou, Y.; Du, X.; Liang, Y.; Li, B. A new CrFeNi2Al eutectic high entropy alloy system with excellent mechanical properties. J. Alloys Compd. 2019, 770, 655-661. [CrossRef]

49. Jin, X.; Zhou, Y.; Zhang, L.; Du, X.; Li, B. A new pseudo binary strategy to design eutectic high entropy alloys using mixing enthalpy and valence electron concentration. Mater. Des. 2018, 143, 49-55. [CrossRef]

50. Liu, D.; Yu, P.; Li, G.; Liaw, P.K.; Liu, R. High-temperature high-entropy alloys AlxCo15Cr15Ni70-x based on the Al-Ni binary system. Mater. Sci. Eng. A 2018, 724, 283-288. [CrossRef]

51. Yin, Y.; Kent, D.; Tan, Q.; Bermingham, M.; Zhang, M.X. Spheroidization behaviour of a Fe-enriched eutectic high-entropy alloy. J. Mater. Sci. Technol. 2020, 51, 173-179. [CrossRef]

52. Jin, X.; Zhou, Y.; Zhang, L.; Du, X.; Li, B. A novel Fe20Co20Ni41Al19 eutectic high entropy alloy with excellent tensile properties. Mater. Lett. 2018, 216, 144-146. [CrossRef]

53. Huo, W.; Zhou, H.; Fang, F.; Zhou, X.; Xie, Z.; Jiang, J. Microstructure and properties of novel CoCrFeNiTax eutectic high-entropy alloys. J. Alloys Compd. 2018, 735, 897-904. [CrossRef]

54. Jiang, H.; Zhang, H.; Huang, T.; Lu, Y.; Wang, T.; Li, T. Microstructures and mechanical properties of $\mathrm{Co}_{2} \mathrm{MoxNi}_{2} \mathrm{VWx}$ eutectic high entropy alloys. Mater. Des. 2016, 109, 539-546. [CrossRef]

55. Rogal, Ł.; Morgiel, J.; Świątek, Z.; Czerwiński, F. Microstructure and mechanical properties of the new Nb25Sc25Ti25Zr25 eutectic high entropy alloy. Mater. Sci. Eng. A 2016, 651, 590-597. [CrossRef]

56. Shuang, S.; Ding, Z.Y.; Chung, D.; Shi, S.Q.; Yang, Y. Corrosion resistant nanostructured eutectic high entropy alloy. Corros. Sci. 2020, 164, 108315. [CrossRef]

57. Lu, Y.; Jiang, H.; Guo, S.; Wang, T.; Cao, Z.; Li, T. A new strategy to design eutectic high-entropy alloys using mixing enthalpy. Intermetallics 2017, 91, 124-128. [CrossRef]

58. Mukarram, M.; Mujahid, M.; Yaqoob, K. Design and development of CoCrFeNiTa eutectic high entropy alloys. J. Mater. Res. Technol. 2021, 10, 1243-1249. [CrossRef]

59. Wang, Z.; Wu, M.; Cai, Z.; Chen, S.; Baker, I. Effect of Ti content on the microstructure and mechanical behavior of (Fe36Ni18Mn33Al13)100-xTix high entropy alloys. Intermetallics 2016, 75, 79-87. [CrossRef]

60. Baker, I.; Meng, F.; Wu, M.; Brandenberg, A. Recrystallization of a novel two-phase FeNiMnAlCr high entropy alloy. J. Alloys Compd. 2016, 656, 458-464. [CrossRef]

61. Wu, Q.; Wang, Z.; Zheng, T.; Chen, D.; Yang, Z.; Li, J.; Kai, J.-J.; Wang, J. A casting eutectic high entropy alloy with superior strength-ductility combination. Mater. Lett. 2019, 253, 268-271. [CrossRef]

62. Jiang, H.; Han, K.; Gao, X.; Lu, Y.; Cao, Z.; Gao, M.C.; Hawk, J.A.; Li, T. A new strategy to design eutectic high-entropy alloys using simple mixture method. Mater. Des. 2018, 142, 101-105. [CrossRef]

63. Jiang, H.; Han, K.; Qiao, D.; Lu, Y.; Cao, Z.; Li, T. Effects of Ta addition on the microstructures and mechanical properties of CoCrFeNi high entropy alloy. Mater. Chem. Phys. 2018, 210, 43-48. [CrossRef]

64. He, F.; Wang, Z.; Cheng, P.; Wang, Q.; Li, J.; Dang, Y.; Wang, J.; Liu, C.T. Designing eutectic high entropy alloys of CoCrFeNiNbx. J. Alloys Compd. 2016, 656, 284-289. [CrossRef]

65. Jiang, L.; Lu, Y.; Dong, Y.; Wang, T.; Cao, Z.; Lu, Y. Effects of $\mathrm{Nb}$ addition on structural evolution and properties of the $\mathrm{CoFeNi}_{2} \mathrm{~V}_{0.5}$ high-entropy alloy. Appl. Phys. A 2015, 119, 291-297. [CrossRef]

66. Vrtnik, S.; Guo, S.; Sheikh, S.; Jelen, A.; Koželj, P.; Luzar, J.; Kocjan, A.; Jagličić, Z.; Meden, A.; Guim, H.; et al. Magnetism of CoCrFeNiZrx eutectic high-entropy alloys. Intermetallics 2018, 93, 122-133. [CrossRef]

67. Rahul, M.R.; Phanikumar, G. Design of a Seven-Component Eutectic High-Entropy Alloy. Metall. Mater. Trans. A 2019, 50, 2594-2598. [CrossRef]

68. Chen, X.; Qi, J.Q.; Sui, Y.W.; He, Y.Z.; Wei, F.X.; Meng, Q.K.; Sun, Z. Effects of aluminum on microstructure and compressive properties of Al-Cr-Fe-Ni eutectic multi-component alloys. Mater. Sci. Eng. A 2017, 681, 25-31. [CrossRef]

69. Liu, S.; Gao, M.C.; Liaw, P.K.; Zhang, Y. Microstructures and mechanical properties of AlxCrFeNiTi0.25 alloys. J. Alloys Compd. 2015, 619, 610-615. [CrossRef]

70. Yaqoob, K.; Joubert, J.-M. Experimental investigation of the Mo-Ni-Re system. J. Alloys Compd. 2013, 559, 101-111. [CrossRef]

71. Yaqoob, K.; Joubert, J.-M. Experimental determination and thermodynamic modeling of the Ni-Re binary system. J. Solid State Chem. 2012, 196, 320-325. [CrossRef]

72. Yaqoob, K.; Crivello, J.-C.; Joubert, J.-M. Thermodynamic modeling of the Mo-Ni system. Calphad 2018, 62, 215-222. [CrossRef]

73. Shun, T.-T.; Chang, L.-Y.; Shiu, M.-H. Microstructure and mechanical properties of multiprincipal component CoCrFeNiMox alloys. Mater. Charact. 2012, 70, 63-67. [CrossRef] 
74. Mathieu, R.; Dupin, N.; Crivello, J.C.; Yaqoob, K.; Breidi, A.; Fiorani, J.M.; David, N.; Joubert, J.M. CALPHAD description of the Mo-Re system focused on the sigma phase modeling. Calphad 2013, 43, 18-31. [CrossRef]

75. Yaqoob, K.; Guénée, L.; Cerný, R.; Joubert, J.-M. A modulated structure derived from the phase in the Mo-Ni-Re system. Intermetallics 2013, 37, 42-45. [CrossRef] 